\section{Reproducibility of individual response to exposure to high altitude}

The response of people who live at sea level to the low oxygen concentrations at high altitude varies widely. Some people are relatively unaffected while others suffer severe acute mountain sickness. ${ }^{1}$ Anecdotal reports and experiments in decompression chambers have indicated that responses to high altitude are reproducible ${ }^{2}$ but this has been difficult to substantiate under controlled field conditions. A two year study of the staff manning an astronomical observatory $4200 \mathrm{~m}$ above sea level permitted an examination of individual performance during repeated ascents. ${ }^{3}$

\section{Methods and results}

The $3.8 \mathrm{~m}$ United Kingdom infrared telescope is sited at the summit of Mauna Kea $(4200 \mathrm{~m})$ in Hawaii. Staff alternately work on the mountain for five days and rest at sea level for five days. During work shifts they sleep at $3000 \mathrm{~m}$ and work for 10 hours at the summit. The daily ascent from $3000 \mathrm{~m}$ to $4200 \mathrm{~m}$ takes 30 minutes by vehicle. Self assessment questionnaires listing the symptoms of acute mountain sickness and scoring their severity on a scale of 0 to 10 were completed by 18 men (aged 17-45) during two separate five day shifts at the telescope. Arterial capillary blood was drawn from the ear lobes of 12 men on days 1 and 5 of each shift. Oxygen and carbon dioxide tensions were measured with an Instrumentation laboratory IL213 analyser.

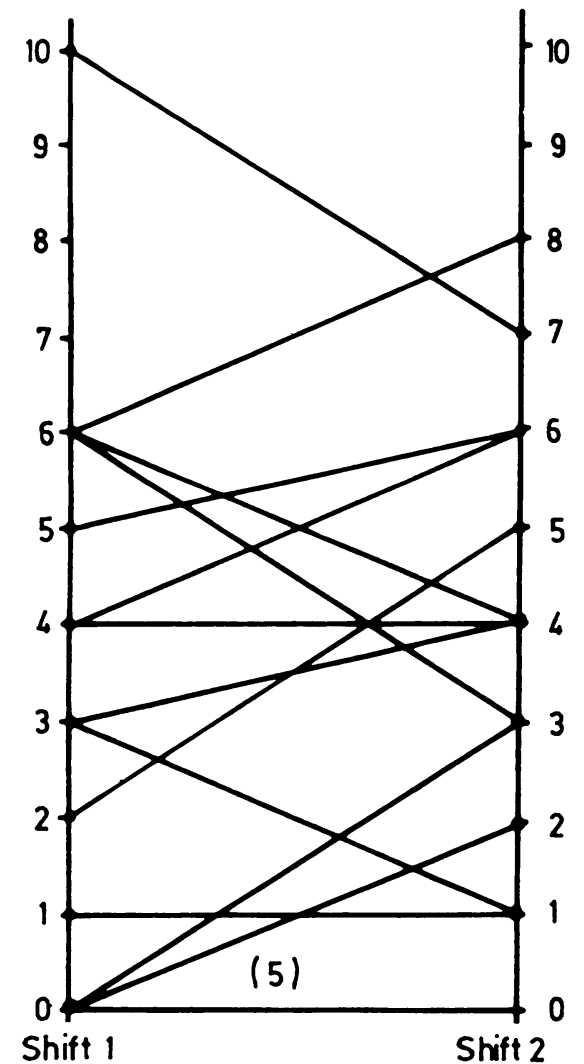

Comparison of scores for symptoms of altitude sickness recorded by 18 men on day 1 of two five day work shifts at $4200 \mathrm{~m}$.

Five men were asymptomatic at the summit. The remaining 13 experienced characteristic symptoms of acute mountain sickness (headache, lethargy, insomnia, and anorexia). The figure shows that the order of the 18 men ranked according to severity of altitude sickness on the first day of the two shifts correlated significantly $(r=0.63, p<0.001$, Kendall's rank test $)$. After five days on the mountain most workers were free of symptoms.

Arterial oxygen tension on day 1 of the two shifts ranged from $4.4 \mathrm{kPa}$ $(33 \mathrm{~mm} \mathrm{Hg})$ and $5.1 \mathrm{kPa}(38 \mathrm{~mm} \mathrm{Hg})$ in one man to $7.0 \mathrm{kPa}(53 \mathrm{~mm} \mathrm{Hg})$ and $7.6 \mathrm{kPa}(57 \mathrm{~mm} \mathrm{Hg})$ in another; the mean for the group was $5.5 \mathrm{kPa}(41 \mathrm{~mm}$ $\mathrm{Hg})$. The two values for each man correlated well $(r=0.74, p<0.01)$. The order of men ranked according to arterial oxygen tension on day 1 of the first shift correlated with that on the second shift $(p<0.05)$. Individual workers' oxygen tensions were similar on day 5 of the two shifts $(r=0.67$; $\mathrm{p}<0.02)$, and in the two men mentioned above were $5.1 \mathrm{kPa}(38 \mathrm{~mm} \mathrm{Hg})$ and $5.7 \mathrm{kPa}(42 \mathrm{~mm} \mathrm{Hg})$ in one and $6.7 \mathrm{kPa}(50 \mathrm{~mm} \mathrm{Hg})$ and $7.9 \mathrm{kPa}(59 \mathrm{~mm} \mathrm{Hg})$ in the other.

Mean arterial carbon dioxide tension was higher on the first shift $(3.9$ $(\mathrm{SD} 0.52) \mathrm{kPa}(29(3.91) \mathrm{mm} \mathrm{Hg}))$ than on the second $(3.5(0.54 \mathrm{kPa}(26$ $(4 \cdot 1) \mathrm{mm} \mathrm{Hg})$ ), but there was a significant correlation between the values on the two ascents $(p<0.01)$. Carbon dioxide tension correlated inversely with oxygen tension $(r=-0.62 ; p<0.001)$. Assuming a gas exchange ratio of 0.8 and an inspired oxygen tension of $12.5 \mathrm{kPa}(94 \mathrm{~mm} \mathrm{Hg})$ at $4200 \mathrm{~m}$, the mean (SD) alveolar to arterial oxygen tension gradient was $2 \cdot 1(0 \cdot 64)$ on day 1 and $2.0(0.62)$ on day 5 . These values are comparable with a mean gradient of $2 \cdot 2(0 \cdot 9)$ at sea level.

\section{Comment}

Some telescope operators suffered from acute mountain sickness on each ascent to $4200 \mathrm{~m}$ while others reported no symptoms. Lack of judgment and denial of symptoms are well recognised features of acute mountain sickness. Nevertheless, self assessment has been shown to be as reliable as peer review in assessing the severity of acute mountain sickness in supervised people. ${ }^{4}$ Arterial oxygen and carbon dioxide tensions were similar for each man on the two ascents, indicating a reproducible degree of hypoxia and hyperventilation on exposure to high altitude.

The inherent characteristic that determines susceptibility to altitude sickness is unknown, but experimental evidence suggests that susceptibility may be inversely related to the ventilatory drive to hypoxia. The oxygen tension gradient did not increase on ascent. This observation confirmed the clinical impression that pulmonary oedema was not a causal factor in the hypoxia of our subjects.

1 Hackett PH, Rennie D, Levine HD. The incidence, importance, and prophylaxis of acute mountain sickness. Lancet 1976 ;ii:1149-54.

2 Robinson SM, King AB, Aoki V. Acute mountain sickness: reproducibility of it severity and duration in an individual. Aerospace Medicine 1971;42:706-8.

3 Forster PJG. Work at high altitude: a clinical and physiological study at the United Kingdom infrared telescope, Mauna Kea, Hawaii. Edinburgh: Royal Observatory,

4 Fletcher RF, Wright AD, Jones GT, Bradwell AR. The clinical assessment of 5 Milledge JS. Acute mountain sickness. Thorax 1983;38:641-5.

(Accepted 8 August 1984)

Department of Pathology, Royal Liverpool Hospital, Liverpool L69 3BX

PETER FORSTER, MD, MRCP, medical research iellow

Correspondence to: Dr P Forster, Rheumatic Diseases Unit, Northern General Hospital, Edinburgh EH5 2DQ.

\section{Sublingual glyceryl trinitrate compared with Nitrolingual spray using cardiac scintigraphy}

Glyceryl trinitrate is administered sublingually to treat acute angina and for prophylaxis, but the tablets have poor stability and a shor half life, and absorption may be delayed, especially in patients who have dry mouths or are edentulous. A new way of administration avoids these problems and may retain the advantages of rapid absorption via the oral mucosa. Studies of an aerosol solution (Nitrolingual spray, Pohl-Boskamp) have shown appreciable improvements in ejection fraction, pulmonary wedge pressure, and exercise tolerance. ${ }^{1-3}$ We conducted a trial comparing haemodynamic changes induced by the spray and sublingual glyceryl trinitrate.

\section{Patients, methods, and results}

We studied 10 patients (eight men, two women) aged 49-75 (mean 63) with stable angina. Eight had had myocardial infarction but none had clinical or radiological evidence of heart failure. All were accustomed to using nitrates in some form but did not take long acting nitrates within 24 hours or sublingual nitrates within two hours of the tests. No patient was currently taking calcium channel blockers. All gave informed written consent.

We compared the haemodynamic effects of the two methods of administration by assessing changes in heart rate using an electrocardiogram, blood pressure using a sphygmomanometer, and left ventricular ejection fraction using a single crystal scintillation probe (Nuclear Stethoscope, Bios Incorporated, United States). ${ }^{4}$ Patients rested for 40 minutes beforehand and 
lay supine throughout the investigation. Red blood cells were labelled in vivo by intravenous injections of $15 \mathrm{mg}$ stannous pyrophosphate followed by about $444 \mathrm{MBq}(12 \mathrm{mCi})$ technetium-99 pertechnetate after 15 minutes. We used standard positioning techniques ${ }^{5}$ to position the probe over the left ventricle where the maximum stroke volume curves were recorded (these points were marked on patients' chests) and to obtain background readings.

We measured three baseline ejection fractions for each patient; maximum variation was $9 \%$ (mean $4.5 \%$ ). Glyceryl trinitrate was then administered to five patients as a $500 \mu \mathrm{g}$ sublingual tablet and to five by two puffs of the spray $(800 \mu \mathrm{g})$, which was used in a way we thought to be consistent with the manufacturer's instructions. (The canister was shaken and then held vertically $2 \mathrm{~cm}$ from the mouth, delivery was directed at the surface of the tongue, and patients were instructed not to swallow or inhale the spray.) Ejection fractions were recorded at five minute intervals for 30 minutes.

One hour after ejection fractions had returned to baseline values (about two hours after the first dose of nitrate) the tests were repeated using the alternative administration. The background reading was checked before each administration. Patients were asked to report any symptoms after administration of the drug.

Administration of both preparations provoked a similar slight rise in heart rate but no consistent change in supine blood pressure. The figure shows that changes in ejection fraction were significantly less five minutes after two puffs of Nitrolingual spray than after $500 \mu \mathrm{g}$ glyceryl trinitrate sublingually $(\mathrm{p}<0.005)$.

The manufacturers found that the canisters used in the experiments contained $83 \%$ of their nominal content of glyceryl trinitrate.

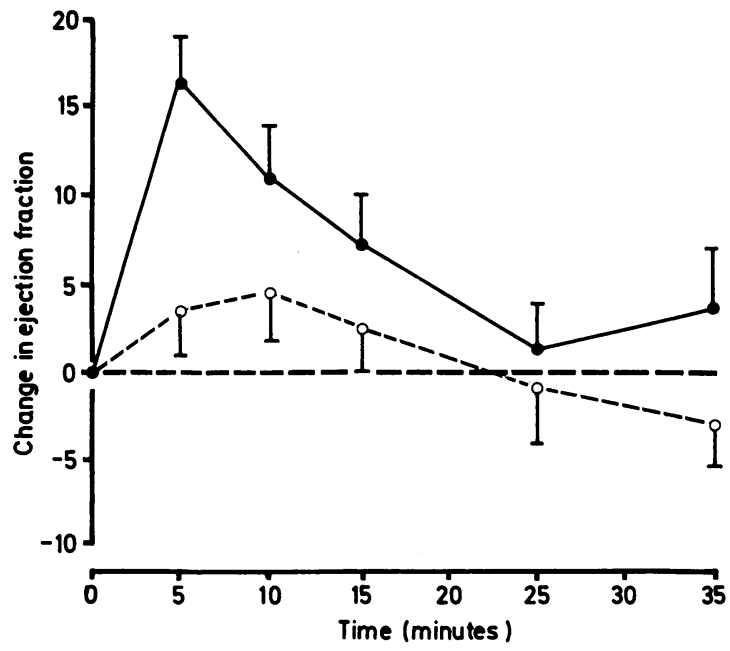

Mean (SE) change in left ventricular ejection fraction (\%) after administration of sublingual glyceryl trinitrate $(O)$ and Nitrolingual spray $(O)$ to 10 patients with stable angina.

\section{Comment}

Most authorities accept that benefits of nitrates depend, at least in part, on systemic vascular effects. We concluded from our data that Nitrolingual spray, used in apparent accordance with the manufacturer's instructions at the time, produced a less pronounced haemodynamic response than conventional sublingual glyceryl trinitrate. Our results differed from those of studies conducted elsewhere in Europe, possibly because British doctors and patients are accustomed to "shaking before use." Discussions with the manufacturers of Nitrolingual spray provoked by these results showed that shaking the canister may produce bubbles that impede delivery of the active agent.

A comparison of the two formulations in healthy subjects, in which plasma glyceryl trinitrate concentrations were measured, confirmed our results, but subsequent experiments with a modified canister head and without shaking produced bioavailability data for the spray showing a slightly larger area under the curve than that produced by the sublingual product (D E Davies, personal communication). Recommendations against shaking will therefore be printed on the packaging, and the canister head modified.

Nitrolingual spray was supplied by Lipha Pharmaceuticals Limited. We thank Mr T M Brown of Lipha and the manufacturer of Nitrolingual (G Pohl-Boskamp) for their efficient cooperation in identifying the cause of our discrepant haemodynamic data. The curve showing plasma glyceryl trinitrate concentrations obtained with the old and the modified canisters will be made available on request to us (by permission of $\mathrm{Mr} \mathrm{D}$ E Davies of Simbec Research Limited and G Pohl-Boskamp).
Chevigné $M$, Renier J, Rigo P, Denioulin $P$, Collignon $P$, Kulbertus HE. Efficacy of nitroglycerine in spray form. Rev Med Interne 1980;1:265-72. trinitrate spray at rest and during exercise in a sitting position. Cardiology $1982 ; 69: 84-90$

3 Kimchi A, Lee G, Amsterdam E, Fujii K, Krieg P, Mason DT. Increased exercise tolerance after nitroglycerin oral spray: a new and effective therapeutic modality in angina pectoris. Circulation 1983;67:124-7

4 Bacharach SL, Green MV, Jeffrey SB, Ostraw HG, Redwood DR, Johnson GS ECG gated scintillation probe measurement of left ventricular function. $\mathscr{f}$ Nucl Med 1977;18:1176-83.

5 Berger HJ, Davies RA, Batsford WP, Hoffer PB, Gottschalk A, Zaret BL. Beatto-beat left ventricular performance assessed from the equilibrium cardia blood pool using a computerized nuclear probe. Circulation 1981;63:133-42.

(Accepted 17 August 1984)

Royal Sussex County Hospital, Brighton BN2 5BE

MARY HEBER, MB, MRCP, cardiac registrar

R VINCENT, MD, MRCP, consultant cardiologist

D A CHAMBERLAIN, MD, FRCP, consultant cardiologist

Correspondence to: Dr D A Chamberlain.

\section{Blast injury of the lungs due to lightning}

Several reports of injuries sustained as a result of lightning strikes have previously been published. These, however, have principally recorded the results of the electrical component of the incident. I report on a patient who survived a lightning strike but sustained extensive bilateral pulmonary contusions and a perforated tympanic membrane, both attributable to the blast wave alone.

\section{Case history}

An 18 year old Zambian man was admitted to this hospital on 5 December 1983. He was conscious but knew nothing of how he came to be in hospital. The history was obtained from two witnesses. The previous evening they had been crossing open bush country in a thunder storm and walking widely separated from each other. A lighning bolt struck somewhere very near to the patient, whom they found shortly afterwards lying on the ground. After several minutes he was able to rise to his feet and with their help completed the journey home. During the evening his breathing became increasingly laboured, and he was brought to hospital. He did not vomit.

On examination his respiratory rate was 80 breaths/minute at rest. His pulse rate was 118 beats/minute and regular, and his blood pressure was $100 / 70 \mathrm{~mm} \mathrm{Hg}$. Surgical emphysema was found in the right supraclavicula fossa extending up the right side of the neck. He was not cyanosed. Auscultation showed extensive bilateral pulmonary crepitations. The left tympanic membrane was ruptured (the right was obscured by wax). A

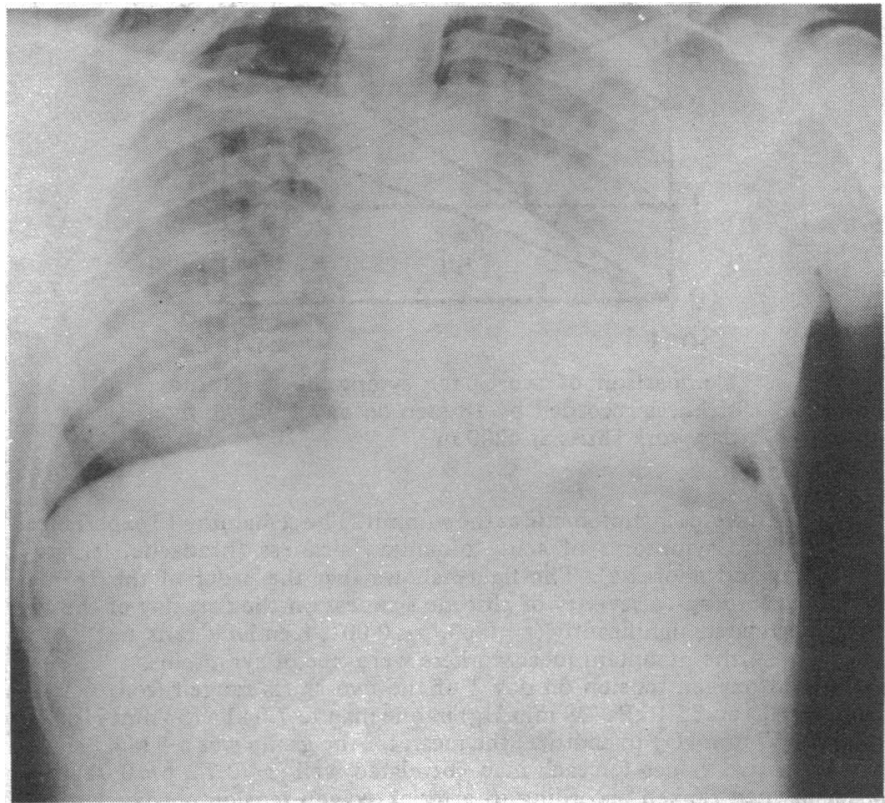

Chest radiograph showing bilateral patchy consolidation with mediastinal and right supraclavicular emphysema and no fractures. 